\title{
Increased ischemia-modified albumin levels in patients with gastric cancer
}

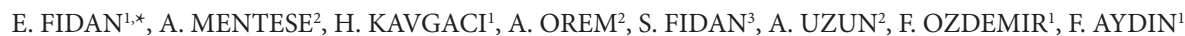 \\ ${ }^{1}$ Division of Medical Oncology; ${ }^{2}$ Department of Biochemistry; ${ }^{3}$ Division of Gastroenterology, Karadeniz Technical University Faculty of \\ Medicine,Trabzon, Turkey
}

${ }^{*}$ Correspondence: evrenfidan@yahoo.com

Received November 12, 2011 / Accepted February 1, 2012

\begin{abstract}
Reactive oxygen species (ROS) are found in the development stages of carcinogenesis.
Fifty two patients with gastric cancer and 35 controls were enrolled in this trial. IMA, MDA, Total Oxidant Status (TOS), Total Antioxidant Status (TAS) and Oxidative Stress Index (OSI) were evaluated.

There was a significant increase in IMA and MDA levels in the patient group $(0.405 \pm 0.111,0.271 \pm 0.066 ; p=0.0001$ and $0.207 \pm 0.251,0.077 \pm 0.103 ; p=0.004$ respectively). TOS was also higher in the patient group but it was not statistically different. TAS was statistically lower and there was significant difference in OSI $(0.621 \pm 0.394,0.996 \pm 0.37 ; \mathrm{p}=0.0001$ and $9.68 \pm 18.2$, $2.9 \pm 3.85 ; p=0.001$ respectively). The areas under receiver operating characteristics curves for the determination of gastric cancer were 0.842 for IMA and 0.708 for MDA.

Increased levels of IMA, MDA and oxidative stress index were detected and this condition is associated with the impairment of oxidant-antioxidant balance.
\end{abstract}

Key words: ischemia modified albumin, gastric cancer, oxidative stress

Gastric cancer is one of the common cancer types in the world with a high rate of mortality. According to the United States data, the number of new cases is 21.000 and the number of estimated deaths is 10.570 in 2010 (1). Generally, gastric cancer is detected in advanced stage and its prognosis is poor.

Reactive oxygen species (ROS) are found in the development stages of carcinogenesis and there is a growing interest about this subject. ROS include hydroxyl radicals, superoxide anion radicals and lipid peroxyl radicals, and they may have two different effects on cell cycle. Elevated levels of ROS cause tissue injury or DNA damage. Depending on their concentrations they may be secondary messengers stimulating the signal transduction in the cell and characterizing the viability of cancer cell. In addition, they also have antitumorogenic effects that lead to apoptosis $(2,3)$.

Ischemia-modified albumin (IMA) is a product generated from albumin as a response of hypoxia (4). Acidosis, superoxide radicals, free iron, and copper ions may lead to the IMA formation. Increased IMA levels were detected in cerebrovascular and peripherovascular disease, advanced liver failure, prostatic diseases, and cancer (5). Malondialdehyde (MDA) is a product of lipid peroxidation; it increases in hypoxic conditions and it is a marker of oxidative stress $(6,7)$.
Gupta et al. examined oxidative stress parameters in patients with non-small cell lung cancer and studied lipid peroxidation products, glutation, nitric oxid and superoxide dismutase as oxidative stress parameters (8). Kersepovic et al. performed another study in patients with breast cancer and examined antioxidant status and lipid peroxidation (9). However, there is no study in the literature about oxidative stress parameters in patients with gastric cancer. This study was performed on the basis of this finding and we decided to evaluate the differences between patients and healthy controls with regard to these parameters.

\section{Patients and Methods}

Patients. Fifty two gastric cancer patients and thirty five controls (age matched) were enrolled in this case-control trial. Patients were selected from the Medical Oncology Clinic of Karadeniz Technical University, Faculty of Medicine, and who had been referred from other practitioners. Patients were staged according to the seventh edition of the American Joint Committee. Blood samples were collected from patients and control subjects on admission, from the antecubital vein in tubes containing EDTA and Na-citrate. 
Plasma supernatants were obtained after the centrifugation of blood samples at $3000 \mathrm{rpm}$ for 10 minutes. The remaining serum and plasma samples were kept at $-80{ }^{\circ} \mathrm{C}$ until biochemical analyses.

Measurement of Ischemia Modified Albumin Levels. Reduced cobalt to albumin binding capacity (IMA level) was analyzed using the rapid and colorimetric method of Bar-Or et al. (10). Two hundred microliter $(\mu \mathrm{L})$ of patient $\mathrm{Na}$-citrate plasma was placed into glass tubes and $50 \mu \mathrm{L}$ of $0.1 \%$ cobalt chloride (Sigma, $\mathrm{CoCl}_{2} \cdot 6 \mathrm{H}_{2} \mathrm{O}$ ) in $\mathrm{H}_{2} \mathrm{O}$ was added. After gentle shaking, the solution was left for 10 minutes, in order to ensure sufficient cobalt albumin binding. Fifty $\mu \mathrm{L}$ of dithiothreitol (DTT) (Sigma, $1.5 \mathrm{mg} / \mathrm{ml} \mathrm{H}_{2} \mathrm{O}$ ) was added as a colorizing agent and the reaction was quenched 2 minutes later by adding $1.0 \mathrm{~mL}$ of $0.9 \% \mathrm{NaCl}$. A colorimetric control was prepared for preoperative and postoperative serum samples. For the colorimetric control samples, $50 \mu \mathrm{L}$ of distilled water was substituted for $50 \mu \mathrm{L}$ of $1.5 \mathrm{mg} / \mathrm{mL}$ DTT. Specimen absorbencies were analyzed at $470 \mathrm{~nm}$ by a spectrophotometer (Shimadzu UV1601, Australia). The color of the DTT containing specimens was compared with that of the colorimetric control tubes. The results were reported as absorbance units (ABSUs).

Serum MDA Activity Assay. Lipid peroxidation in human serum samples was determined as MDA concentration using the method described by Yagi (11). Briefly, $2.4 \mathrm{~mL}$ of N/12 $\mathrm{H}_{2} \mathrm{SO}_{4}$ and $0.3 \mathrm{~mL}$ of $10 \%$ phosphotungstic acid were added to $0.3 \mathrm{~mL}$ serum. After being allowed to stand at room temperature for $5 \mathrm{~min}$, the mixture was centrifuged at $1600 \mathrm{~g}$ for $10 \mathrm{~min}$. Discard supernatant and sediment was suspended in $4 \mathrm{ml}$ of distilled water. Subsequently, $1 \mathrm{~mL}$ of $0.67 \%$ thiobarbituric acid was added, and the mixture was heated in boiling water for $60 \mathrm{~min}$. The mixture was centrifuged at $1600 \mathrm{~g}$ for $10 \mathrm{~min}$. The absorbance of the organic layer was read at $532 \mathrm{~nm}$. Tetramethoxypropane was used as a standard and MDA levels were calculated as $\mathrm{nmol} / \mathrm{ml}$.

Measurement of Total Oxidant Status (TOS). TOS of serum was determined using a novel-automated measurement method as previously described (12). Serum TOS levels were calculated in $\mu \mathrm{mol} \mathrm{H}_{2} \mathrm{O}_{2}$ equivalent/L.

Table 1. Demographic and clinical characteristics of patients with gastric adenocarcinoma $(\mathrm{n}=52)$

\begin{tabular}{ll}
\hline $\begin{array}{l}\text { Characteristics } \\
\text { Gender }\end{array}$ & Number of patients (\%) \\
Female & $21(40)$ \\
Male & $31(60)$ \\
Age, mean & $57.27 \pm 12.90$ \\
Disease stage & \\
IIA & $2(3.85)$ \\
IIB & $5(9.62)$ \\
IIIA & $7(13.46)$ \\
IIIB & $5(9.62)$ \\
IIIC & $9(17.30)$ \\
IV & $24(46.15)$ \\
\hline
\end{tabular}

Measurement of Total Antioxidant Status (TAS). The total antioxidant status of the serum was determined using a novel-automated measurement method developed by Erel (13). Serum TAS levels were calculated in mmol Trolox equivalent/L.

Calculation of Oxidative Stress Index (OSI). TOS : TAS ratio was used as OSI. To perform the calculation, the units of TAC, mmol Trolox equivalent/L, were converted to mmol Trolox equivalent $/ \mathrm{L}$, and OSI was calculated as follows: OSI = [(TOS, $\mu \mathrm{mol} \mathrm{H}_{2} \mathrm{O}_{2}$ equivalent/L) / (TAS, $\mu \mathrm{mol}$ Troloxequivalent/L) x 100] (14).

Statistical analysis. The normality of data distribution was examined by using the Kolmogorov-Smirnov test. The differences between the gastric cancer patients and control subjects were investigated by independent-t test for data with normal distribution (IMA and TAS), and by the Mann-Whitney U-test for data that did not display a normal distribution (TOS, OSI and MDA). Pearson's correlation coefficient analysis was used to examine the relationship between the IMA levels and other clinical parameters. $p$ values of less than 0.05 were considered as significantly different.

\section{Results}

Fifty two patients with gastric adenocarcinoma and thirty five age-matched controls were included in this trial (a total of 87 participants). There was no statistically significant difference between the patients and the control group with respect to age $(\mathrm{p}=.544)$. Only twenty four patients had metastasis. Non-metastatic patients were classified into stages according to the seventh edition of the American Joint Committee among themselves. Blood samples were collected from all patients before chemotherapy and all patients had adenocarcinoma.

$40 \%(n: 21)$ of patients were female and $60 \%$ (n:31) were male. In control group 21 of the controls were male and the others were female. Mean age in the patient group was $57.27 \pm 12.90$, and $55.34 \pm 16.46$ in the control group. Baseline characteristics of patients are provided in Table 1.

IMA levels were evaluated in patients and controls. There was a significant increase in IMA levels in the patient group ( patients; $0.405 \pm 0.111$, controls; $0.271 \pm 0.066 \mathrm{p}=0.0001$ ). The patient group were staged as stage IV and stage II-III and, according to IMA levels there was no significance between these groups ( $p>0.05)$. MDA levels were studied for detecting the difference between patients and controls. MDA levels were statistically higher in gastric cancer patients ( patients; $0.207 \pm 0.251$, controls; $0.077 \pm 0.103, p=0.004$ ). TOS was higher in the patient group but it was not statistically different $(\mathrm{p}>0.05)$. TAS was evaluated and there was a statistically significiant difference between patients and controls with respect to TAS levels. TAS was lower in patients $(\mathrm{p}=0.0001)$. OSI was studied for evaluating the balance between TOS and TAS. This parameter was found to be higher in gastric cancer patient group $(\mathrm{p}=0.01)$. MDA, TOS, TAS and OSI were interpreted between stages in patient group. There were no 
statistically significant difference between stage IV and stage II-III patients with respect to these parameters ( $p>0.05)$. All findings are shown in Table 2 . For all gastric cancer patients, there was no significant correlation between serum IMA levels and MDA levels, TAS, TOS and OSI $(\mathrm{r}=-0.359, \mathrm{P}=0.592 ; \mathrm{r}=$ $-0.523, \mathrm{P}=0.537 ; \mathrm{r}=-0.451, \mathrm{P}=0.421 ; \mathrm{r}=-0.138, \mathrm{P}=0.828$, respectively).

IMA, MDA, TAS and OSI levels were also evaluated with ROC curve analysis. Cut off points, sensitivity \%, specificity \%, positive predictive value (PPV) and negative predictive value (NPV) for the parameters are demonstrated in Table 3 and Figures 1, 2.

\section{Discussion}

Cancer development is a multi-stage process and ROS-mediated DNA damage plays an important role in these stages, especially in initiation and promotion processes (15). Hydroxyl radicals, peroxide and superoxides are ROSs and they are produced also in normal cells. However, if ROS generation increases, tissue damage or DNA damage is observed (3). Hydroxyl radicals may cause base modification and genomic instability by interacting with purines or pyrimidins (15). They may also contribute to the durability of the cancer cell by causing activation in intracellular signal pathways (3). Antioxidant enzyme systems also contribute to achieving intracellular ROS balance. Besides, impairment in oxidant-antioxidant balance leads to oxidative damage in the cells (4). Low levels of antioxidants play a role in carcinogenesis. Glutathion (GSH) and superoxide dismutase (SOD) in antioxidants protect cells from oxidative damage (8). In this study, total oxidant capacity in the patient group was detected to be high, if not statistically significant. Antioxidant capacity, on the other hand, was low compared to the control group. In order to reach a more meaningful result and eliminate erroneous negativities, oxidative stress index in patients was also evaluated and found to be higher in the patient group compared to the controls. This finding supports the observation that reactive oxygen radicals are higher in patients with gastric adenocancer and that lower antioxidant levels contribute to carcinogenesis.

IMA and MDA as other important parameters were also studied in our patients. IMA is a parameter first detected in 1990 s and accepted to reveal tissue ischemia (5). It is detected to have increased not only in myocardial ischemia but also in other ischemic conditions. Some of these conditions include liver and kidney failures, acute infections, prostate diseases, intrauterine events and cancer (5). In this study, IMA levels of patients were also high. Patients did not have manifestations of acute infection and or liver and kidney failures. Stencel et al., in a study they conducted with pediatric cancer patients,

Table 2. Oxidative stress parameters in patients with gastric adenocarcinoma

\begin{tabular}{|c|c|c|c|c|}
\hline \multirow[t]{2}{*}{ Parameter } & \multicolumn{4}{|c|}{ Group } \\
\hline & Patient & Control & Stage IV & Stage II-III \\
\hline $\mathrm{N}$ & 52 & 35 & 24 & 28 \\
\hline $\operatorname{MDA}(\mathrm{nmol} / \mathrm{mL})$ & $0.207 \pm 0.251^{\mathrm{b}}$ & $0.077 \pm 0.103$ & $0.209 \pm 0.251$ & $0.208 \pm 0.255$ \\
\hline TAS(mmolTroloxEquiv./L) & $0.621 \pm 0.394^{\mathrm{a}}$ & $0.996 \pm 0.37$ & $0.576 \pm 0.41$ & $0.654 \pm 0.386$ \\
\hline TOS $\left(\mu \mathrm{molH}_{2} \mathrm{O}_{2}\right.$ Equiv./L) & $23.6 \pm 19.3$ & $22.07 \pm 12.8$ & $20.21 \pm 18.66$ & $30.81 \pm 31.5$ \\
\hline OSI & $9.68 \pm 18.2^{\mathrm{c}}$ & $2.9 \pm 3.85$ & $7.24 \pm 15$ & $11.5 \pm 20.3$ \\
\hline
\end{tabular}

Note:

${ }^{a} P=.0001$ compared with control

${ }^{\mathrm{b}} \mathrm{P}=.004$ compared with control

${ }^{\mathrm{c}} P=.001$ compared with control

Table 3. The optimum diagnostic IMA, MDA, TAS and OSI cutoff point, sensitivity and specifificity according to the receiver operator characteristic (ROC) curve, PPV and NPV

\begin{tabular}{|c|c|c|c|c|c|}
\hline & Cutoff Point & $\begin{array}{c}\text { Sensitivity }(\%)(95 \% \\
\text { CI })\end{array}$ & $\begin{array}{l}\text { Specificity }(\%) \\
\quad(95 \% \mathrm{CI})\end{array}$ & $\begin{array}{l}\text { PPV }(\%) \\
(95 \% \mathrm{CI})\end{array}$ & $\begin{array}{l}\text { NPV }(\%) \\
(95 \% \mathrm{CI})\end{array}$ \\
\hline $\begin{array}{l}\text { İMA } \\
\text { (ABSU) }\end{array}$ & $>0.280$ & $\begin{array}{c}88.5 \\
(76.6-95.6)\end{array}$ & $\begin{array}{c}73.5 \\
(55.6-87.1)\end{array}$ & $\begin{array}{c}83.6 \\
(71.1-92.3)\end{array}$ & $\begin{array}{c}80.6 \\
(62.5-92.5)\end{array}$ \\
\hline $\begin{array}{l}\text { MDA } \\
(\mathrm{nmol} / \mathrm{mL})\end{array}$ & $>0.06$ & $\begin{array}{c}66.7 \\
(52.1-79.2)\end{array}$ & $\begin{array}{c}74.1 \\
(53.7-88.9)\end{array}$ & $\begin{array}{c}82.9 \\
(67.7-92.9)\end{array}$ & $\begin{array}{c}51.4 \\
(34.0-68.6)\end{array}$ \\
\hline $\begin{array}{l}\text { TAS } \\
\text { (mmolTroloxEquiv./L) }\end{array}$ & $<=0.87$ & $\begin{array}{c}80.4 \\
(66.1-90.6)\end{array}$ & $\begin{array}{c}71.4 \\
(53.7-85.4)\end{array}$ & $\begin{array}{c}78.7 \\
(64.3-89.3)\end{array}$ & $\begin{array}{c}73.5 \\
(55.6-87.1)\end{array}$ \\
\hline OSI & $>2.1$ & $\begin{array}{c}77.6 \\
(63.4-88.2)\end{array}$ & $\begin{array}{c}61.8 \\
(43.6-77.8)\end{array}$ & $\begin{array}{c}74.5 \\
(60.2-85.8)\end{array}$ & $\begin{array}{c}65.6 \\
(46.8-81.4)\end{array}$ \\
\hline
\end{tabular}


a

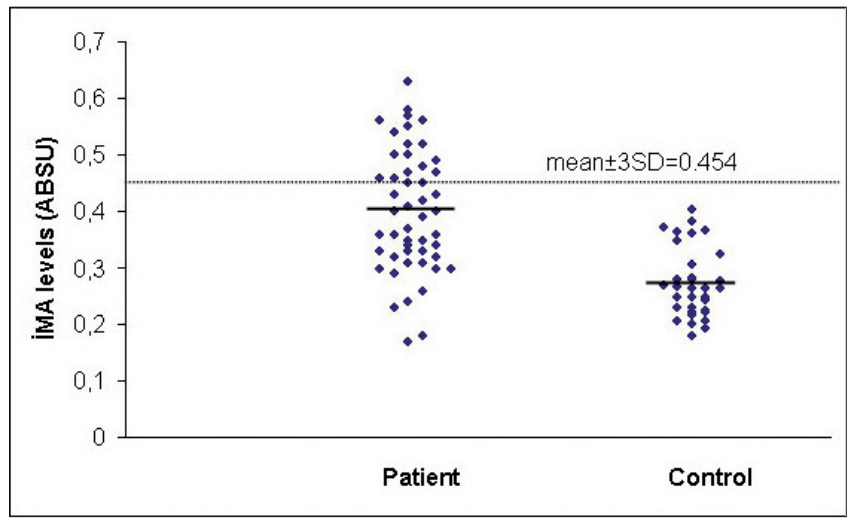

b

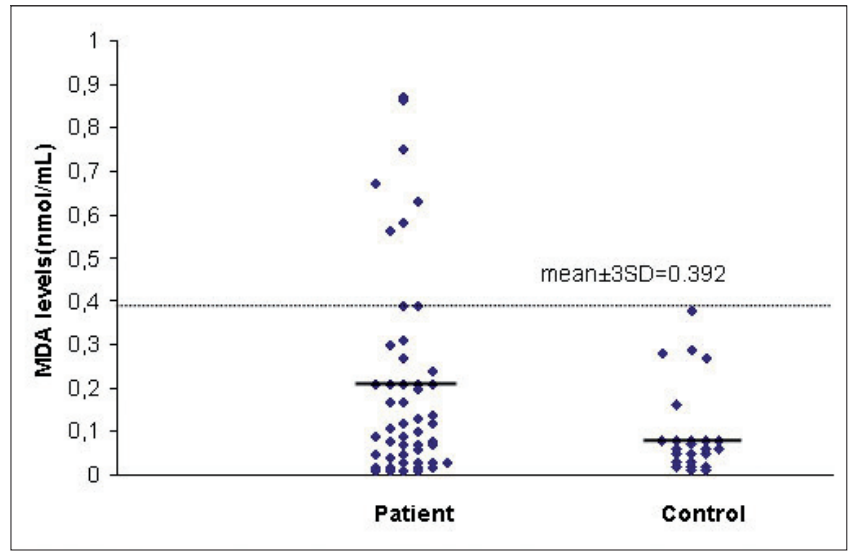

C

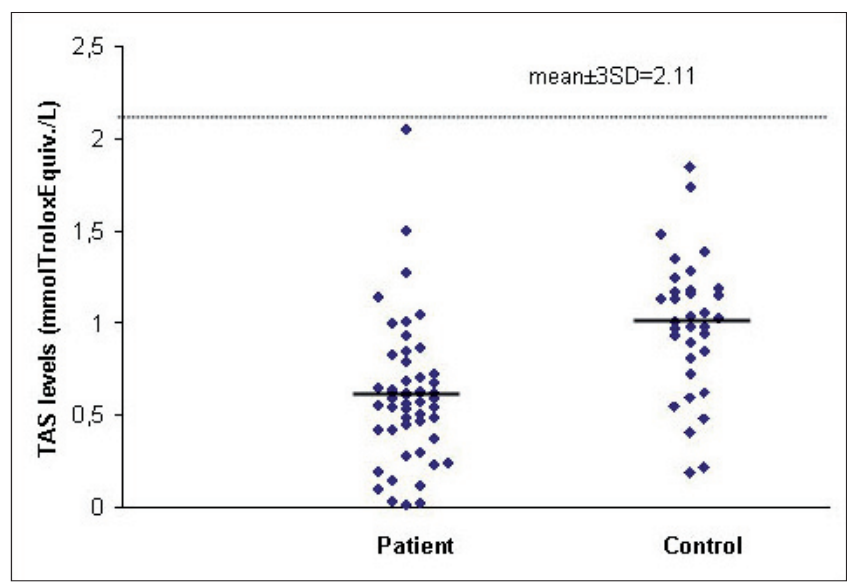

Figure1. a: IMA levels compared with control

b: MDA levels compared with control

c: TAS levels compared with control

evaluated IMA levels and found them to be higher in the patient group compared to the controls (16). In another study conducted with patients with prostate disease and myocardial a

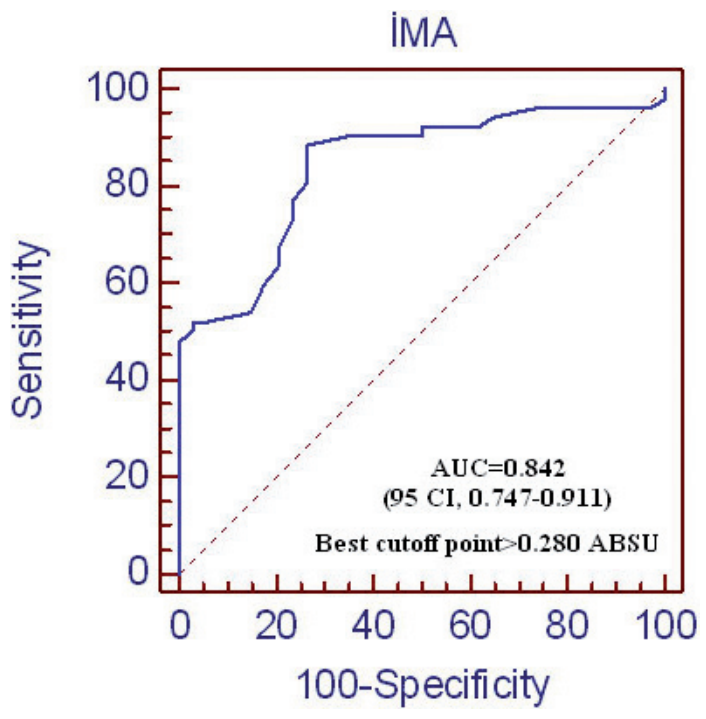

b

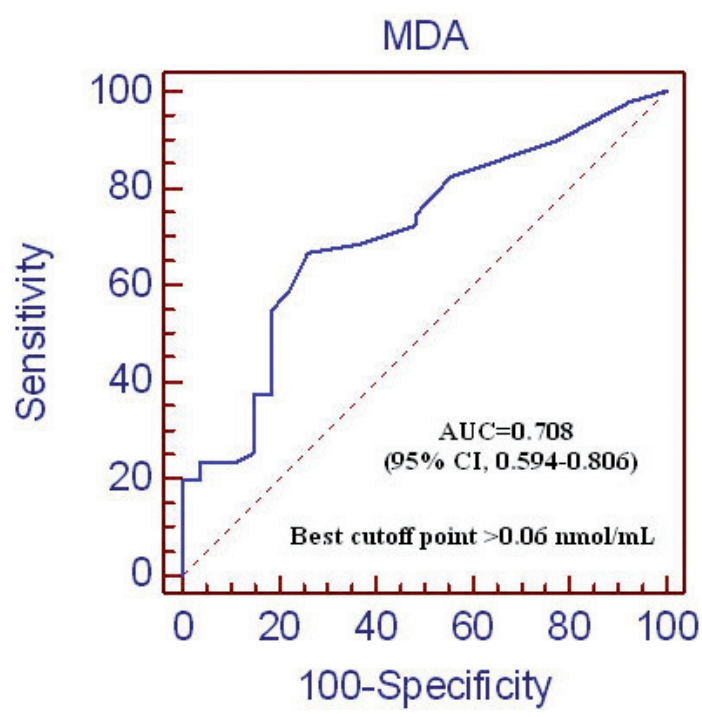

Figure 2. a: The Roc curve of IMA

b: The Roc curve of MDA

infarction, IMA was detected to be high in those with prostate hyperplasia and myocardial ischemia, while no difference was observed in prostate cancer patients (17). Our study is the first in literature which detected high IMA levels in gastric cancer patients.

MDA is a lipid peroxidation product, and is mutagenic and carcinogenic. It causes deoxyguanine and deoxyadenine formation by interacting with DNA, and this interaction leads to the formation of pyrimidopurine called MIG $(18,19)$. In some studies, MDA levels were found to be higher in cancer patients. MDA levels were elevated also in studies conducted with larynx, colon and breast cancer patients. A study with gastric cancer patients also revealed higher MDA levels compared to the control group (7). Similarly, MDA levels were high in our patients. 
According to the ROC analysis IMA and other parameters were evaluated. IMA is more sensitive than MDA to distinguish cancer or not. So, IMA may be a promising marker for gastric cancer.

Consequently, increased levels of IMA, MDA and oxidative stress index were detected in gastric cancer patients, and this condition may be associated with the impairment of oxidantantioxidant balance. This observation is also supported by the decrease in antioxidant capacity. When it is considered that prostaglandins play a role in gastric cancer pathogenesis, high MDA level is likely to be associated with lipid peroxidation and prostaglandin synthesis. This condition supports gastric cancer development pathogenesis. Yet, further studies are needed to establish the relationship of IMA, MDA and oxidative stress parameters with treatment response in gastric cancer and disease prognosis.

\section{References}

[1] American Cancer Society.: Cancer Facts and Figures 2010. Atlanta, Ga: American Cancer Society, 2010

[2] VALKO M, RHODES CJ, MONCOL J, IZAKOVIC M, MAZUR M. Free radicals, metals and antioxidants in oxidative stress-induced cancer. Chem Biol Interact. 2006; 160: 1-40. http: //dx.doi.org/10.1016/j.cbi.2005.12.009

[3] KHANDRIKA L, KUMAR B, KOUL S, MARONI P, KOUL HK. Oxidative stress in prostate cancer. Cancer Lett. 2009; 282: 125-36. http: //dx.doi.org/10.1016/j.canlet.2008.12.011

[4] STACHOWICZ-STENCEL T, SYNAKIEWICZ A, OWCZARZAK A, ALEKSANDROWICZ-WRONA E, SLIWINSKA $\mathrm{A}$, et al. The antioxidant status and response to therapy in children with soft tissue sarcomas and neuroblastoma. Pediatr Blood Cancer. 2011; 57: 561-8. http: //dx.doi.org/10.1002/ pbc. 23014

[5] SBAROUNI E, GEORGIADOU P, VOUDRIS V Ischemia modified albumin changes - review and clinical implications. Clin Chem Lab Med. 2011; 49: 177-84

[6] KEKEC Y, PAYDAS S, TULI A, ZORLUDEMIR S, SAKMAN G, et al Eur J Intern Med. 2009; 20: 403-6. Antioxidant enzyme levels in cases with gastrointesinal cancer. http: //dx.doi. org/10.1016/j.ejim.2008.12.003

[7] BAKAN E, TAYSI S, POLAT MF, DALGA S, UMUDUM Z, et al. Nitric oxide levels and lipid peroxidation in plasma of patients with gastric cancer. Jpn J Clin Oncol. 2002; 32: 162-6. http: //dx.doi.org/10.1093/jico/hyf035

[8] GUPTA A, SRIVASTAVA S, PRASAD R, NATU SM, MITTAL $\mathrm{B}$, et al. Oxidative stress in non-small cell lung cancer patients after chemotherapy: association with treatment response. Respirology. 2010; 15: 349-56 http: //dx.doi.org/10.1111/ j.1440-1843.2009.01703.x

[9] KASAPOVIC J, PEJIC S, STOJILJKOVIC V, TODOROVIC A, RADOSEVIC-JELIC L, et al. Antioxidant status and lipid peroxidation in the blood of breast cancer patients of different ages after chemotherapy with 5-fluorouracil, doxorubicin and cyclophosphamide. Clin Biochem. 2010; 43: 1287-93 http: //dx.doi.org/10.1016/j.clinbiochem.201 $\underline{0.08 .009}$

[10] BAR-OR D, LAU E, WINKLER JV. A novel assay for cobaltalbumin binding and its potential as a marker for myocardial ischemia-a preliminary report. J Emerg Med. 2000; 19: 311-315 http: //dx.doi.org/10.1016/S0736-4679(00)00255-9

[11] YAGI K. Lipid peroxides and related radicals in clinical medicine. Free Radicals in Diagnostic Medicine. New York: Plenum Press; 1994. p. 1-15.

[12] EREL O. A new automated colorimetric method for measuring total oxidant status. Clin Biochem 2005; 38: 1103-1111. http: //dx.doi.org/10.1016/j.clinbiochem.2005.08.008

[13] EREL O. A novel automated method to measure total antioxidant response against potent free radical reactions. Clin Biochem 2004; 37: 112-119. http: //dx.doi.org/10.1016/ j.clinbiochem.2003.10.014

[14] AYCICEK A, EREL O, KOCYIGIT A. Decreased total antioxidant capacity and increased oxidative stress in passive smoker infants and their mothers. Pediatr Int 2005; 47: 635-639 http: //dx.doi.org/10.1111/j.1442-200x.2005.02137.x

[15] ZIECH D, FRANCO R, PAPPA A, PANAYIOTIDIS MI Reactive oxygen species (ROS)--induced genetic and epigenetic alterations in human carcinogenesis Mutat Res. 2011; 711: 167-73. http: //dx.doi.org/10.1016/j.mrfmmm.2011.02.015

[16] STACHOWICZ-STENCEL T, SYNAKIEWICZ A, OWCZARZAK A, SLIWINSKA A, ALEKSANDROWICZ-WRONA $\mathrm{E}$, et al Ischemia-modified albumin as a biochemical marker in children with neuroblastoma and soft tissue sarcomas. J Clin Lab Anal. 2011; 25: 255-8. http: //dx.doi.org/10.1002/ jcla.20469

[17] MASTELLA AK, MORESCO RN, DA SILVA DB, BECKER AM, DUARTE MM, et al. Evaluation of ischemia-modified albumin in myocardial infarction and prostatic diseases. Biomed Pharmacother. 2009; 63: 762-6. http: //dx.doi. org/10.1016/j.biopha.2008.12.002

[18] BLAIR IA Lipid hydroperoxide-mediated DNA damage. Exp Gerontol. 2001; 36(9): 1473-81. http: //dx.doi.org/10.1016/ $\underline{\text { S0531-5565(01)00133-4 }}$

[19] MARNETT LJ Lipid peroxidation-DNA damage by malondialdehyde. Mutat Res. 1999; 424: 83-95. 